\title{
Editorial
}

\section{A Estratégia Saúde da Família: \\ Percalços de uma Trajetória}

| Kenneth Rochel de Camargo Jr. |

A Estratégia Saúde da Família (ESF) é um dos eixos fundamentais da ação do setor público na área de saúde. A característica básica da proposta, em implantação há mais de uma década em nosso país, é prover a atenção básica em saúde, aumentando o acesso da população aos serviços de saúde, com base numa modalidade de atendimento que visa à transformação do modelo assistencial (BRASIL, 2008).

A ESF tem sido objeto de considerável atenção pelos pesquisadores da área de Saúde Coletiva no Brasil, sendo o próprio Ministério da Saúde financiador e parceiro institucional de importantes iniciativas de pesquisa e avaliação (ver, por exemplo, BRASIL, 2002a, 2002b e 2005). O vasto corpo de literatura produzido por pesquisadores brasileiros, em permanente desenvolvimento, esquadrinha as várias dimensões da ESF (e de seu antecessor, o Programa de Saúde da Família), seguindo as diversas linhas estruturais da saúde coletiva, da gestão à formação de recursos humanos, do monitoramento e avaliação com base em indicadores tradicionais à repercussão cultural da implantação da estratégia em diversos contextos sociais e geográficos.

A Estratégia Saúde da Família já foi tema de outras edições de Physis; voltamos a visitá-la neste número, tentando porém apresentar novos ângulos para sua reflexão. No primeiro artigo, Romano aborda os impasses da atuação dos médicos num contexto que se supõe de "mudança de modelo" sob o prisma da identidade profissional, a partir do estudo de um conjunto de médicos de família trabalhando no município do Rio de Janeiro. A autora conclui que a tensão entre uma formação que privilegia a perspectiva biomédica e a prática que demanda maior atenção às dimensóes sociais e intersubjetivas - parte da tensão estruturante descrita por Bonet (2003) - aponta para uma identidade simultaneamente em crise e em construção, com o duplo signo de uma política institucional que encontra dificuldades para a implementação efetiva 
de seus objetivos, mas que ao mesmo tempo cria condições para a emergência de novas modalidades de atenção à saúde.

Esta transição incompleta é de certa forma o que também apontam Garbois et al., a partir de pesquisa fundada na ótica do direito à saúde, seguindo os princípios constitucionais da Carta de 1988. As autoras mostram, com base em estudo documental e entrevistas com informantes-chave sobre a implementação da ESF do Estado do Rio de Janeiro, como ainda é distante o sonho da saúde universal como direito dos cidadãos, ainda que apontando a importância do SUS e da ESF para que esse princípio seja contemplado ao menos como imagem-objetivo.

Encerrando o tema, Eckert et al. discutem as percepções de usuários e da equipe de saúde da família com base em estudo empírico realizado num município no interior do Rio Grande do Sul. As autoras mostram como, apesar de existirem importantes divergências de percepção entre famílias e equipes (por elas denominadas de "ecos discordantes"), ainda assim predomina uma leitura favorável à ESF, com a esperança de progressiva melhoria da assistência na atenção básica.

Tomados em conjunto, esses estudos apontam para obstáculos concretos à efetiva implementação da ESF, e em especial a desejada mudança do modelo assistencial, mas ao mesmo tempo oferecem indicações para possíveis pontos de intervenção para a superação de tais obstáculos.

$\mathrm{Na}$ seção de temas livres, temos os artigos de Mesas et al., que descrevem os problemas de saúde bucal de idosos restritos ao domicílio no município de Londrina (PR); Gomes e Menezes apresentam uma análise dos discursos em conflito nas propostas de legislação sobre aborto e eutanásia, analisando-as à luz dos referenciais das ciências sociais e humanas sobre as concepções de "pessoa humana"; Martins et al. analisam a trajetória dos conselhos de saúde como espaços de participação popular e de elaboração da própria percepção de cidadania; Bagrichevsky et al. fazem uma análise crítica sobre a inserção da Educação Física no campo da Saúde Coletiva no Brasil; Mendonça et al., por fim, encerram a seção com um estudo empírico realizado com cuidadores familiares de pessoas com seqüelas de acidentes vasculares cerebrais.

A seção de resenhas apresenta o livro Trabalhadores em Saúde Mental: reforma psiquiátrica, saúde do trabalhador e modos de subjetivação nos serviços de saúde mental, de Tatiana Ramminger, elaborada por Martinho Silva. 
O ano de 2008 marca a chegada de Physis à maioridade, com a publicação do seu $18^{\circ}$ volume. Como já anunciamos em ediçóes anteriores, a partir deste ano a revista passará a contar com quatro edições anuais, e para marcar essa nova etapa de sua história, adotamos nova programação visual, atualizando seu projeto gráfico, mantendo, porém, a identidade visual que marcou nossa trajetória de sucesso.

Por fim, mas não menos importante, desde o final do ano passado, Physis passou a ser indexada também pela base bibliográfica Scopus, além de LILACS, SciELO, Directory of Open Journals e Sociological Abstracts, marcando sua crescente projeção internacional.

\section{Referências}

BONET, O. Aconselhamento médico e diversidade cultural: a busca de um enfoque integral na prática da medicina de família. In: PINHEIRO, R.; MATTOS, R. A. (Orgs.). Construção da integralidade: cotidiano, saberes e práticas em saúde. Rio de Janeiro: Abrasco, 2003. p. 131-146. BRASIL. Ministério da Saúde. Atenção Básica e a Saúde da Família. Disponível em: http:// dtr2004.saude.gov.br/dab/atencaobasica.php. Acesso em: 2 mar. 2008.

- Avaliação da implementação do Programa Saúde da Família em dez grandes centros urbanos: síntese dos principais resultados. Brasília: Ministério da Saúde, 2002b.

- Avaliação na Atenção Básica em Saúde: caminhos da institucionalização. Brasília: Ministério da Saúde, 2005.

. O Programa Saúde da Família: evolução de sua implantação no Brasil. Brasília: Ministério da Saúde, 2002a. 